\title{
Art and science: promoting understanding and empathy through film
}

Version: final accepted and peer reviewed manuscript for article in British Journal of Midwifery, - article published November 2017, Vol 25

\section{Authors}

Shreepali Patel Director of StoryLab, Anglia Ruskin University

Maxine Wallis-Redworth Senior lecturer, course leader Midwifery, Faculty of Health, Social Care and Education, Anglia Ruskin University

Sophie Jackson Senior lecturer, course leader Film and Television Production, Anglia Ruskin University

Lindsey Rose Senior Midwifery lecturer, Faculty of Health, Social Care and Education, Anglia Ruskin University

\section{Abstract}

This paper introduces a cross-disciplinary collaboration that has brought together the disciplines of film (art) and midwifery (art and science) in the utilization of creative documentary to evaluate new learning opportunities and reflective practice for student midwives. The case study film, The Golden Window, (filmed in a Neonatal, Intensive Care Unit [NICU] over 72 hours), was screened to a group of second year midwifery students in the Cambridge Arts Picturehouse, Cambridge, UK prior to their placements in NICU. The students recorded their thoughts and impressions of the film. Their responses are summarised and reflected upon within this paper with the underlying intent to examine whether this innovative interaction between art and 
science can provide an appropriate pedagogic framework for effective learning through creative and artistic means.

\section{Key Words}

6Cs | Empathy | Learning Film | Practice-based process | Innovative | Crossdisciplinary

\section{Learning to Care?}

Modern healthcare is founded on the essential core of caring. Since nursing and midwifery education moved away from traditional apprentice style training into higher education there have been questions raised as to whether the ability to care is innate, or is a skill that can be acquired in clinical practice (Barnett, 2008, Phipps et al. 2015: 333). The concept of the 6 Cs of good practice (care, compassion, communication, competence, courage and commitment) were introduced by NHS England (Cummings, 2012) in order to improve the quality of care for patients following examples of appalling care in Mid Staffordshire hospital. Phipps et al (2015: 333) suggest that, "Caring occurs when communication is good, mutual respect is nurtured and decision making about care is shared".

Power (2015: 654) has noted that safe and effective care in practice is often "informed by evidence-based guidelines developed and implemented by the National Institute for Health and Care Excellence based on hierarchies of evidence, with meta-analyses and systematic reviews being identified as the 'gold standard'." This approach can, however, fail to acknowledge the 'art of midwifery', where a constructivist paradigm of experiential, intuitive and tacit knowledge is used by reflective practitioners to provide high-quality care. Constructivist approaches in 
education advocate student-centred rather than instructor-led teaching and learning. Our study uses Mayer's (2004) concept of guided discovery where the tutor gives the student tools to explore the subject matter. The approach taken by this crossdisciplinary team is rooted in this paradigm. The tool provided was the 23-minute creative documentary The Golden Window (Patel \& Jackson, 2014).

The Golden Window (TGW) was screened during a module on complex health needs of mothers and babies during which they had learnt about prematurity and critically sick neonates and the associated bio psychosocial care for families. Within the safe environment of the cinema/classroom, TGW provided a lens into the Neonatal Intensive Care Unit (NICU) environment that consolidated the theory and brought an element of the experience of NICU to facilitate personal preparation for a challenging placement area. Within the midwifery curriculum, there is an emphasis on the impact of care on families through reflection on practice. In this case, TGW afforded the students an opportunity to nurture their intuitive and reflective skills alongside new knowledge to refine their clinical perceptual and observational skills to recognise and address parental cues (Leap 2000; Cox 2002; Power 2015; Cox). 


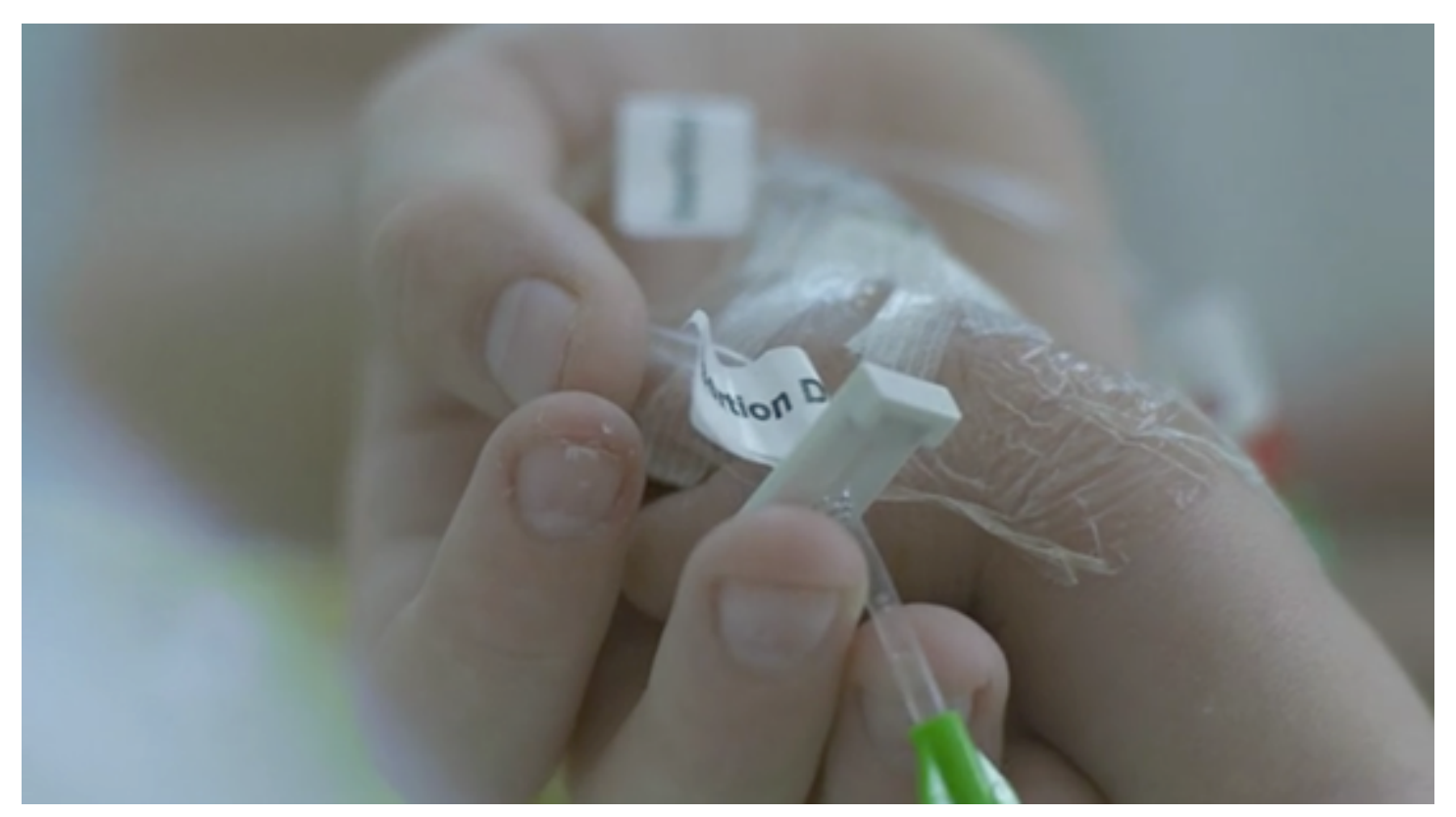

Figure 1. Close ups and shallow focus create something close to the baby's point of view. . Photo The Golden Window/Tim Sidell

\section{The Film}

$T G W$ is a creative documentary shot within 72 hours of opportunity at the Rosie Hospital Neonatal Intensive Care Unit (NICU) at Addenbrookes Hospital, Cambridge. The central storyline follows the medical induced cooling of 'Baby J' after a traumatic birth and interweaves interviews with key staff and parents within the ward. The Director, Dr Shreepali Patel and neonatal consultant Dr Topun Austin made the film as a research project exploring collaboration between Art and Science. This significantly placed the film outside the broadcast commissioning and finance process, which broadly encourages a highly dramatized and formatted television program such as 24 Hours in A\&E (C4) and One Born Every Minute (ITV). The film was not intended to be an informational piece, detailing clinical practice in NICU. Rather the filmmakers (Patel \& Jackson, 2014) take a poetic approach placing the baby and parent's experiences at the centre of the film (figures 1-2). Through 
filmmaking techniques of camera placement, detailed close ups, shallow focus, enhanced sound design the film creates something close to the baby's point of view as a way of introducing NICU to the viewer (figure 1-3). The film also captures contradictory and unanticipated emotions that NICU generates, interweaving the candid and immediate thoughts of parents and staff as they experience this world that the parents refer to as the 'bubble world'. From the close-up intensity of the senses, to the very direct interviews, TGW created an immersive filmic experience whilst also maintaining a fundamental 'truth' of these 72 hours in NICU.

The film was made through mutual and collaborative dialogue between the academic filmmaking team, the staff working in NICU (specifically Dr Austin and his team), and parents looking after their babies within the unit. All procedures were performed in compliance with relevant laws and institutional guidelines and the appropriate institutional committee approved them. The main idea behind the filming was to come to the unit for a few days and 'see what happened'. "Filmmakers, cameramen and sound engineers went about their business in a much more unobtrusive way. Parents, doctors and nurses were invited into a little 'film booth' to speak directly to Shreepali (Patel)... One only has to see the parents to realize how this approach allowed them to open up in a really powerful way” (Austin \& Patel, 2014). 


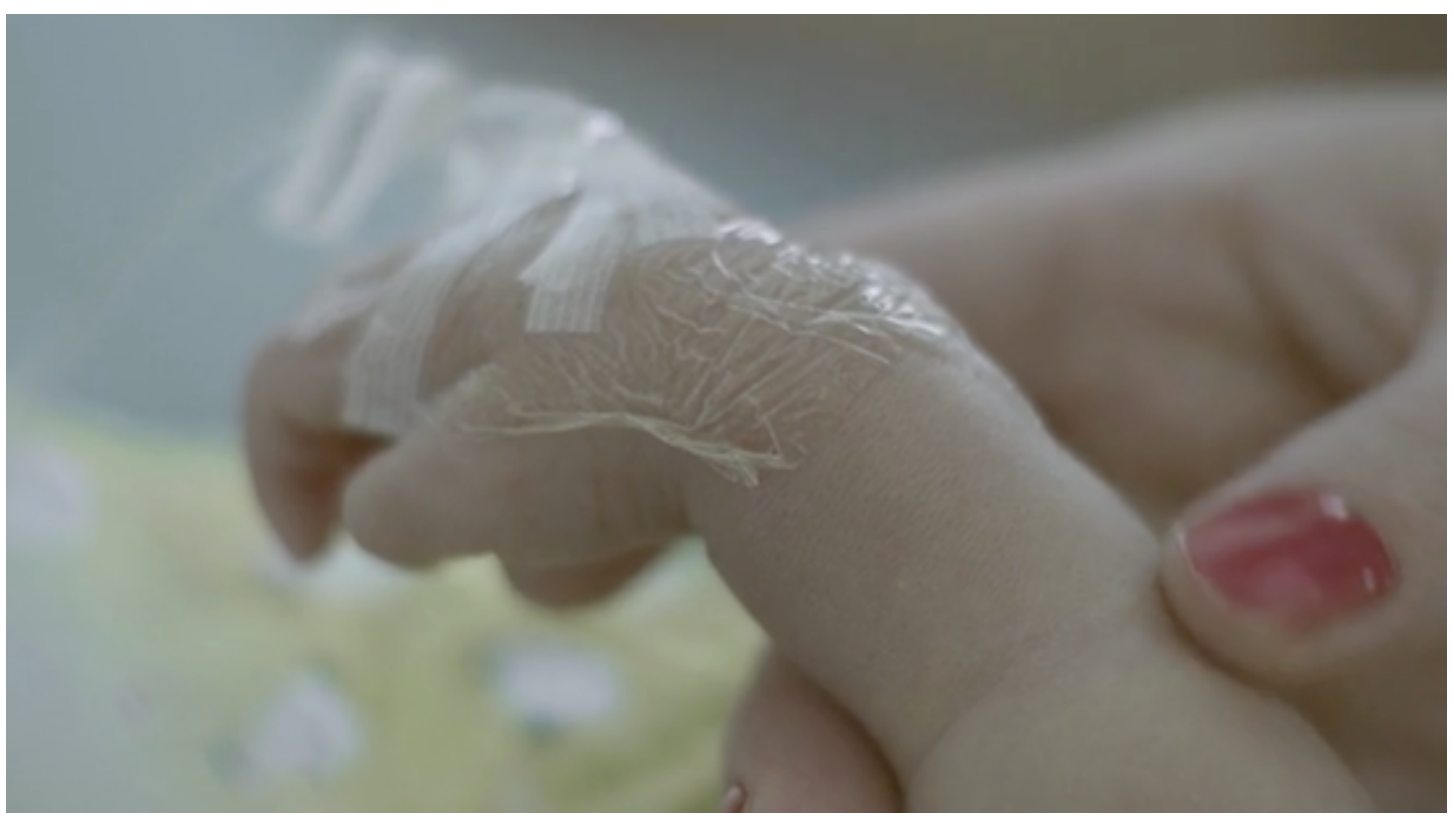

Figure 2. Emotionally-led instincts of touch important to the healing process. Photo The Golden Window/Tim Sidell

This intimate opportunity to open up to someone not directly related to the care of their babies, combined with the immediacy of the circumstances - the interviews were also shot in the 72 hours - allowed the babies' parents to very candidly highlight their experience of NICU - to tell their stories. Reissman (2008) points out that filmic storytelling performs several functions, including a cathartic process of talking to someone, not in this world as either patient or care giver, but there just to observe and listen. Clandinin \& Rosiek (2007) argue that filmed testimonies represent an interpretation of an event or series of events as seen by those individuals, which may be quite different to people working in the same environment, and this theory is played out in TGW, showing the multiplicity of experience in NICU. The three principal testimony-based stories in TGW are from parents: a father, who lost two of his triplets, talks about the "one cuddle a day" he is allowed and differentiates between the "good bleeps" and "bad bleeps" of the machines; a mother (figure 3) who realized that it is only other parents with direct experience of "this bubble world of NICU who really understand"; and another mother whose baby was "whisked 
away" at birth, and despite still being in shock is able to articulate her feelings. Collectively these interviews suggest an experience, which is almost abstract and imperceptible for those 'outside' of this physical space (the 'bubble world') of NICU.

The research nature of the production facilitated a responsive approach to the structure of the film, with the environment of NICU influencing the process as well as the final film. What emerged during the actual filmmaking process was the very real tension between science and emotion, where a 'bleep' on the machines meant something different to a parent, nurse or doctor. "Often the parents felt hopeless in the face of all the machines. However, it became increasingly clear that the emotionally led instincts of touching and talking to the baby by parents were equally as important in the healing process" (Austin \& Patel, 2014). For the filmmakers, this complex mix of science and emotion seemed best evoked by interweaving some aspects of traditional documentary storytelling with a more immersive cinematic experience. The use of heightened sound, macro lenses and movement were all designed to pull the viewer into the "bubble world", through feeling and emotion in order to try and understand this world that the parents inhabited.

This type of creative and immersive filmmaking allows familiar processes and environments to be reframed. TGW asks doctors, nurses and midwives to reevaluate and reflect on the world they feel they know well and reframe their assumptions. For those who have yet to experience this world such as the student midwives, the film frames unexpected, nuanced and alternate experiences that can then feed into their actual experience in NICU and builds on the theory received in the classroom. 


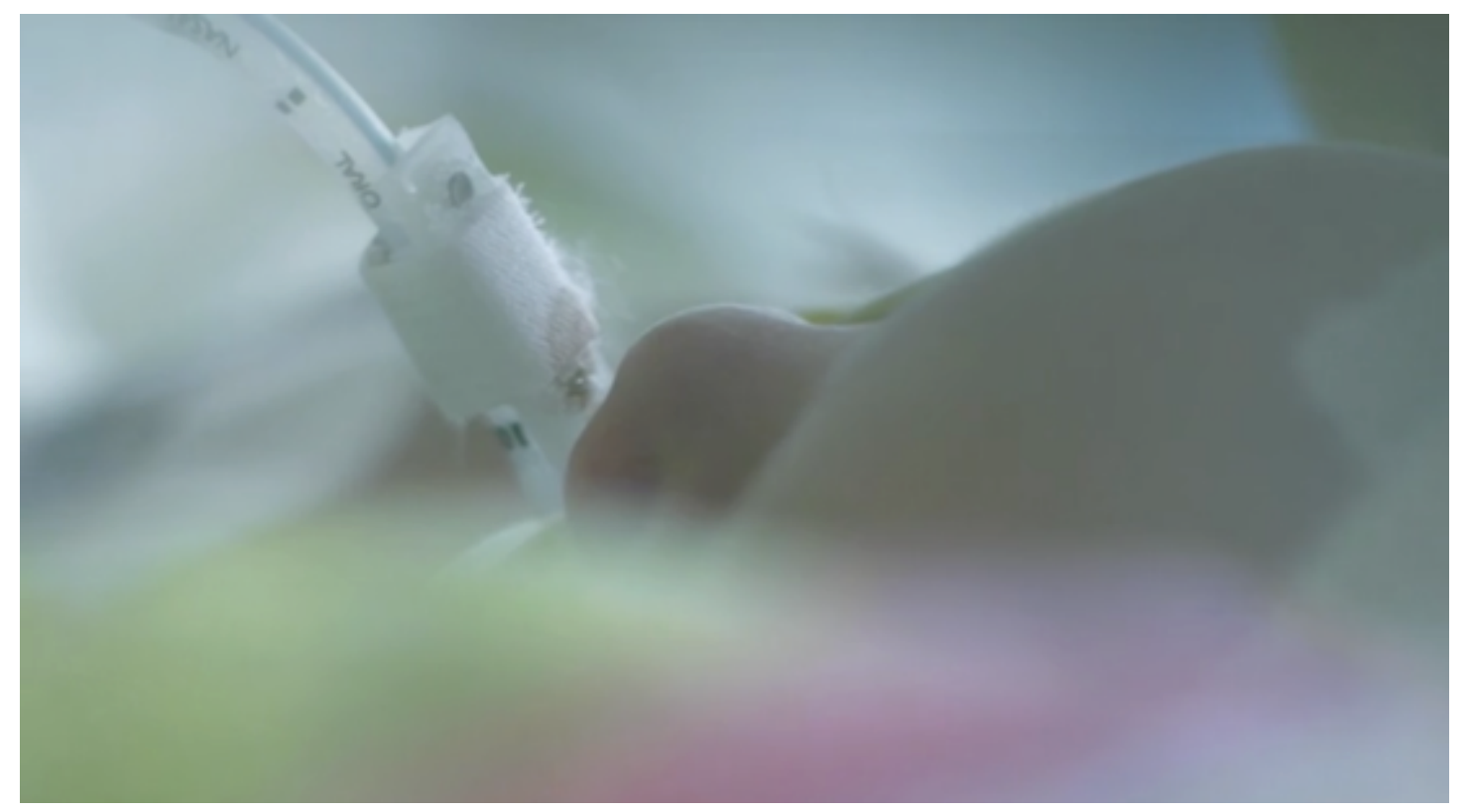

Figure 3. 'Baby J' under medically-induced cooling in the neonatal intensive care unit Photo The Golden Window/Tim Sidell

\section{Screening the film}

TGW was screened to midwifery students at the Cambridge Arts Picturehouse. The filmmakers were interested in the student's response to the creative techniques used and their viewing experience. The midwifery education team wanted to evaluate if seeing the film made any difference in preparing them for clinical placement. We considered this process as an evaluation of teaching and learning. The screening was optional and the students were given the choice as to whether they contributed to pre and post screening comments. Students gave verbal consent for their comments to be used in a publication about the experience of screening this film as part of their curriculum. Obtaining comments from the students was in line with other teaching evaluations that they are exposed to. Following the screening, the students were asked to anonymously evaluate: a) their cinematic experience of watching the film; b) whether the creative techniques used in filmmaking helped 
them to understand the NICU environment; and c) what emotional elements they may have perceived from the film. There was also a group discussion about the key issues the students identified from the viewing. This primarily focused on parental reaction rather than the technicality of the filmmaking. Within the remainder of the module teaching, and during guided reflection sessions in placement, students had opportunity to reflect on the screening in relation to their personal experiences in placement, with the help of the tutors.

Following NICU placements some students provided anonymous comments on the impact of TGW on their learning in line with our usual module evaluation sessions.

\section{Post screening student response}

The response by the students to seeing the film was overwhelmingly positive: 'gripping. Never lost interest', 'effective as if you're seeing and hearing everything as the baby being taken to NICU', 'felt a sense of anticipation and foreboding' suggest that this creative approach was very powerful in drawing them into the 'bubble world', and actually giving them a sense of what it might be like for the parents and babies.

Students noted the impact staff can have on families in NICU: 'how to talk to parents in similar situations and take into account their feelings and that it is abnormal environment for them'; 'An insight into some of the emotions of the parents in NICU and some of the amazing techniques that can be used to help babies that previously may not have lived or would have been very unwell long-term.'

Students reported feelings of empathy, gaining 'a better understanding and appreciation of parents' experiences', 'powerful and humbling, it reminded me why 
I'm doing this job', 'To consider the fear of the parents and the perspective of the baby.' It helped them to consider the impact of their choice of words, 'Talk to the parents, absorb what is happening. Understand that it is a highly charged environment with positive and negative outcomes'.

The feedback suggests that the students all took different things away from the cinema experience and several of them wanted to watch it again on their own, to have time to reflect on what they had seen. Some wanted to satisfy themselves that their initial response was accurate and they had 'noticed all the important bits.' In some cases, they wanted to watch it again because they felt emotionally overwhelmed by the impression it had left on them.

\section{Post NICU student response}

Further feedback was gathered from the students after their NICU placement. TGW enabled students to be less intimidated by the NICU environment: 'I went to NICU after the screening of TGW and I felt prepared for the type of environment I walked into.' 'It helped to make the environment more familiar.' 'The film made me realise how much of an overwhelming experience it might be for parents and how frightened they are of a) what is happening or might happen with their baby, b) how frightening the environment is to them - especially machines and noises.'

Students reported the film enabled them to take a more active role in care provision and supported their understanding of the whole NICU experience. The film encouraged empathy and compassion for the parents and baby: 'As a student 
midwife on NICU the hardest thing is to understand what's wrong with the baby and all the complex procedures they've undergone prior to meeting them.'

It informed their knowledge: 'Due to the sensitive nature of NICU, when parents are present it is, understandably, inappropriate to ask your mentor to explain the condition and the treatment the patient has received. I had no knowledge of head cooling prior to seeing TGW.'

Another student commented 'I realised the huge benefit of seeing TGW when I accompanied a family to an MRI scan to assess the impact of head cooling after birth. I immediately understood the rationale for everything we did that day in NICU, having seen the film.

It gave them confidence to talk to parents and improved communication; 'the film gave me an insight into what the family had been through, which made it easier for me to make conversation with them.' 'TGW enabled me to be a more active part of their care, rather than merely observing.' 'Making conversation with families is extremely daunting on NICU, so I was very grateful to have seen the film.' 'Supporting parents was the aspect I enjoyed most about my NICU placement.' 'It has impacted on my experience on NICU in terms of communicating with parents and reassuring them and supporting both of them.' Students were also able to see beyond the practice placement documentation aspects: 'I felt that it allowed me to take more out of the placement than just clinical skills'.

\section{Post screening response from midwifery educators}


The art and science of midwifery is embedded within the education of student midwives as part of the holistic care provision. There are a number of ways of delivering this to parents and babies that encompass the bio-psychosocial model of care (Downe, 1998; Power, 2015). Midwifery education and practice needs to ensure students are properly prepared to do this. TGW is one example of how different forms of media, art and technology can produce a teaching tool to create simulation of the NICU setting combined with service user perspective. However, TGW was a different experience to more straightforward audiovisual material used in teaching because of the immersive and poetic representation of the NICU world. This experience encouraged them to consider the complexity of social, emotional, spiritual and physical needs of families in their care.

TGW gives midwifery educators a unique chance to enable students to explore the views and feelings of the parents within a safe environment, free from the constraint of the potential for saying or doing the 'wrong thing'. For midwifery, TGW can bring a strong visual impression of the environment. Students can start to appreciate the audio sensations before entering the unit for placement - they can then consider how stressed parents may react to the sounds. They can use this knowledge to prepare parents antenatally or in birth settings before the first visit there. Additionally, the midwifery educators feel it has helped students develop the knowledge and skills to support parents whose babies are being cared for in NICU because they are aware of the multiplicity of responses possible.

TGW emphasizes the importance of empathy, which is the essence of midwifery care. Students watching TGW can 'feel' that empathy when they hear the parent's 
voices as well as the nurses and doctors and this will prepare them for their experiences on NICU as well as helping them to start considering what it means to empathize. One student mentioned the impact of the importance of noise and light, as the film powerfully helped her feel what it might be like to be that baby. Midwifery students unsure of empathy may thus 'get it' from watching TGW and improve their holistic care through this educational approach.

The midwifery team, feel using TGW as a teaching and learning tool to facilitate the students' reflective ability has the potential to increase their confidence to use intuition and enhance their clinical decision-making. This has the potential to impact every clinical area that they work in and serves to ensure that every care episode is maximized to meet the holistic needs of the mother and her family. The team originally felt that they should show the film at the beginning of the second year when students were due to complete their NICU placement. However, due to the positive impact discussed above, the film will now be shown earlier in their degree because it raises so many broader issues about this core holistic element to care provision.

\section{Conclusion}

Art and creative media have the capability to communicate, educate and inspire people in the most powerful ways (Patel \& Toulson, 2013). It can enhance the viewer's intellectual and emotional response to this complex environment, allowing for critical reflection. Indeed, human beings are made up of mind, body and spirit working seamlessly together with faculties such as logical thinking, imagination and 
feelings (Knudsen, 2008), and as such all these faculties should be considered as part of the pedagogic approach to the learning process of student midwives.

It should be noted that the "move from an instructor to a facilitator model of teaching requires commitment and self-reflection on the part of the educator" (Haith-Cooper, 2003) which the team embraced with this particular exercise. Both the film and midwifery teams saw this as a unique opportunity to harness the potential of working with other disciplines to enhance their own educational practices. It was hoped that the students would also embrace the novelty of this new and exciting way of teaching across the two disciplines and take this experience forward into the next stage of their midwifery practice. The aim of the midwifery course is to prepare students for practice and using interesting and varied forms of learning enhance this process.

TGW appeared to be a very effective tool in supporting the experiential learning of the student midwives by bringing a heightened sense of reality of NICU before they reach the Unit, and also sowed the seeds of self-reflection for those with experience of NICU to see their environment through the eyes of the patients and the carers (as evidenced by feedback from evaluative exercise). Such an intuitive approach supports an iterative process from expert knowledge, recognition and reflection to inform future practice (Power, 2015) and facilitates a discussion of 'clinical perception' (Leap, 2000) where practitioners automatically use perceptual observation to notice overt and covert clues from women, parents, patients which they compare to their stored knowledge.

\section{References}


Austin T, Patel S (2014) The Golden Window Exhibition and Presentation. Digital Gallery, Ruskin Gallery, Cambridge Science Festival, Cambridge

Barnett R (2008) Critical professionalism in an age of super-complexity. In:

Cunningham B ed. Exploring Professionalism. Institute of Education, London

Clandinin JD, Rosiek J (2007) Mapping a landscape of narrative inquiry: Borderland spaces and tensions. In: Clandinin JD, ed. Handbook of Narrative Inquiry. Mapping a Methodology. SAGE, Alberta: 35-77

Cox K (2002) Perceiving clinical evidence. Med Educ 36 (12): 1189-95

Cummings $\mathrm{J}$ (2012) Compassion in Practice: Our Culture of Compassionate Care.

Department of Health, London

Downe S (1998) "Caring and sharing: developing the art and science of midwifery", British Journal of Midwifery, 6(7): 427

Haith-Cooper M (2003) An exploration of tutors' experiences of facilitating problem based learning. Part 2-implictions for the facilitation of problem based learning. Nurse Education Today 23(1): 63-75

Knudsen E (2008) 'Transcendental Realism in Documentary" In: Austin T, de Jong W Rethinking Documentary new Perspectives, New Practices, New York, McGrawHill Education

Labov W, Waletzky J (1967) Narrative analysis: oral versions of personal experience. In: Helm J, ed. Essays in the Verbal and Visual Arts. University of Washington Press, Seattle: 12-44

Lakoff G, Johnson M (2003) Metaphors We Live By, 2nd edn. University of Chicago Press, Chicago

Leap N (2000) The less we do, the more we give. In: Kirkham M, ed. The MidwifeMother Relationship. Palgrave Macmillan, Basingstoke: 1-18

Mayer R (2004). "Should there be a three-strikes rule against pure discovery learning? The case for guided methods of instruction". American Psychologist 59(1): $14-19$ 
One Born Every Minute (2010) (Television Series), Dragonfly Film and Television, C4 UK

Patel S, Toulson R (2013) Educating and Enhancing Compassion, Emotion and Reflective Professional Practice through Contemporary Digital Filmmaking. SMART Digital Futures, IOS Press

Patel S, Jackson S (2014) The Golden Window (Film), Eyeline Films, UK

Phipps F, Whitney E, Meddings F, Evans M (2015) Embedding the 6 Cs: Problembased learning the Bradford way. British Journal of Midwifery 23(5): 330-5

Power A (2015) Contemporary midwifery practice: Art, science or both? British Journal of Midwifery 23(9): 654-7

Reissman CK (2008) Narrative Methods for the Human Sciences. Sage Publications, CA

24 Hours in A\&E (2011) (Television Series) The Garden Productions ITV, UK

\section{The Golden Window}

Key Phrases

- Using innovative interaction between art and science can provide a pedagogic framework for 'deep' learning through student-centred rather than instructor-led teaching and learning.

- Nurturing the intuitive skills of the student midwife combined with the iterative process of applying knowledge and reflection can develop both their clinical and perceptual observational skills.

- The Golden Window (TGW) filming process captured the contradictory and unanticipated emotions that NICU generates, creating a filmic experience whilst also maintaining the fundamental 'truth' of 72 hours in NICU.

- The film frames unexpected nuanced and alternate experiences that can feed into the experiences of student midwives who have not experienced NICU and builds on the theory received in the classroom. 
- This experience has helped students develop the knowledge and skills to support parents whose baby is being cared for in NICU because they are aware of the multiplicity of responses possible.

- Using TGW as a teaching and learning tool to facilitate the students' reflective ability has the potential to increase their confidence and competence to use intuition and enhance their clinical decision-making 